\title{
Progress in Synthetic 2D Polymers Obtained at the Air/Water Interface
}

\author{
A. Dieter Schlüter \\ Dedicated to Hans-Ulrich Reissig on the occasion of his $70^{\text {th }}$ birthday
}

\begin{abstract}
Recent breakthroughs in the single crystal approach to synthetic 2D polymers have shifted the limelight onto these long-range ordered sheet-like polymers synthesized at the air/water interface, where one obtains them as laterally macroscopic monolayers without the need for exfoliation. The article presents the most recent monomers for this approach and shows an important analytical development in the field of structure elucidation as well as findings relevant to potential applications. The analytical development concerns an indirect method to establish crystallinity of 2D polymer monolayers based on a combination of tip-enhanced Raman spectroscopy and a crystallization model. The more application-oriented aspects concern the use of ordered 1-1.5 nm thick monomer arrays for laser-triggered writing and for a novel type of lithography both based on a two-dimensional polymerization.
\end{abstract}

Keywords: 2D materials · Monolayers · Photochemistry · Porous sheets · Two-dimensional polymerization

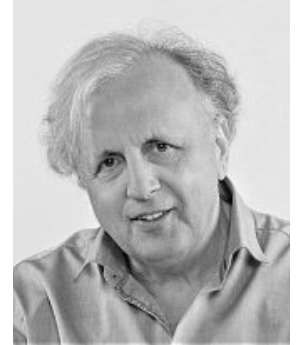

Prof. Dr. A. Dieter Schliuter is, since 2018, professor emeritus for polymer chemistry at the Materials Department of the ETH Zürich. He studied chemistry and geophysics at the University of Munich where he also received his PhD. After stations at UC Berkeley, USA, University of Durham, UK, and the Max-Planck Institute for Polymer Research, Mainz, Germany, in 1991 he became professor for polymer chemistry at the Technical University of Karlsruhe. From 1992 on he was full professor for organic and macromolecular chemistry at the Free University of Berlin until in 2004 he moved to ETH Zürich, where he has been ever since. His research interests are in the area of polymer synthesis.

\section{Introduction}

Until a feasible way of extending Staudinger's famous 'Makromolekül'-concept ${ }^{1]}$ (German for macromolecule) into two dimensions was discovered in 2012,[2] 'infinitely' extended and long-range ordered covalent monolayer sheets were an unmet challenge of synthetic polymer chemistry. ${ }^{[3]}$ This extension initiated considerable research activity in several laboratories and within a matter of a few years, not only a number of valuable exploratory studies towards rational synthesis of 2D polymers were conducted but also a variety of structurally rather different synthetic representatives were obtained. ${ }^{[4]}$ These novel and intriguing sheet-like macromolecules have in common that they are just one monomer unit thick (typically 1-2 nm) and consist of a regular array of monodisperse pores with diameters typically about $2 \mathrm{~nm}$ (Fig. 1). Given these structural features, synthetic 2D polymers have been sometimes called molecular scale fishing nets, ${ }^{[5]}$ which is a useful comparison because everybody is familiar with reallife fishing nets and the structural regularity, softness and strength they exhibit. These properties are also found in their molecular counterparts, the $2 \mathrm{D}$ polymers.

\footnotetext{
${ }^{*}$ Correspondence: Prof. Dr. A. D. Schlüter

E-mail: ads@mat.ethz.ch

Department of Materials, Polymer Chemistry, ETH Zürich, Vladimir-Prelog-Weg 5, $\mathrm{CH}-8093$ Zurich
}

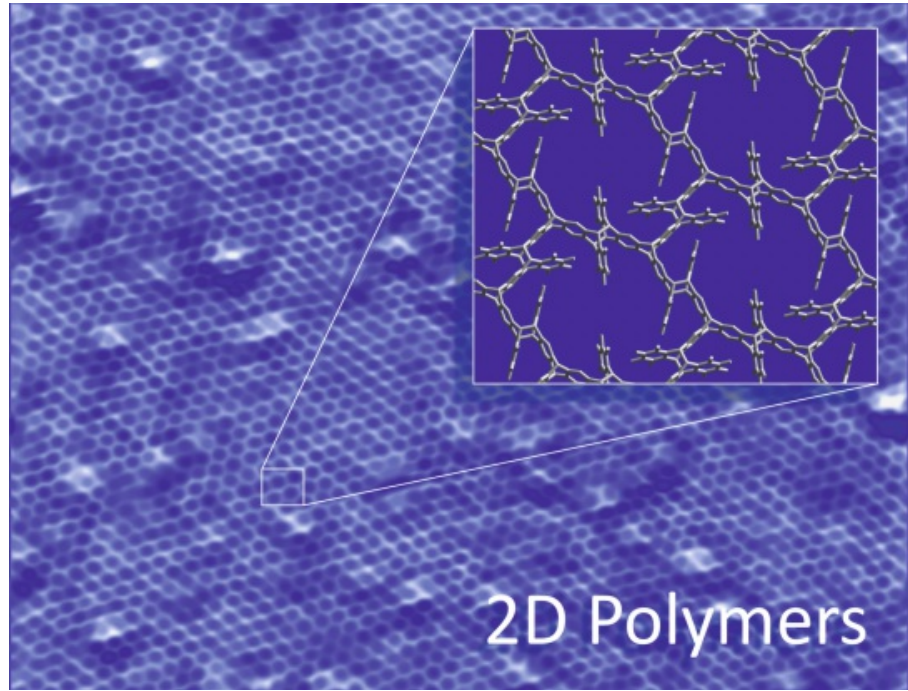

Fig. 1. Non-contact mode high-resolution atomic force micrograph of a monolayer 2D polymer deposited directly from the air/water interface on somewhat impure highly oriented pyrolytic graphite recorded in ultrahigh vacuum by the two-pass technique. The inset provides a structural model based on single crystal X-ray diffraction of a closely related 2D polymer with the exact same network structure. Both the image and the model in the inset show the pores contained in this sheet-like entity. Graphics created by Gregor Hofer.

The two currently dominant synthesis strategies to $2 \mathrm{D}$ polymers are the single crystal- and the air/water interface approach. In the first, layered single crystals in which the monomers in each layer assume a 'reactive packing' are photochemically converted into single crystals composed of stacks of $2 \mathrm{D}$ polymers. ${ }^{[6]}$ In the second, monomers are spread into monolayers at the air/water interface preferably in a 2D crystalline 'reactive packing', which is subsequently converted photochemically into a $2 \mathrm{D}$ polymer monolayer, ${ }^{[7]}$ like the one shown in Fig. 1. ${ }^{[8]}$ Other approaches such as those in homogenous solution, ${ }^{[9]}$ by on-surface growth ${ }^{[10]}$ and by covalent fixation of self-assembled precursors have also been advertised.[11] The whole activity was flanked by explorations towards woven monolayered structures, which - provided 
proper substitution - have the potential to be subsequently converted into their covalently connected analogues. ${ }^{[12]}$ Finally, there are fascinating reports devising ways how to bridge ${ }^{[13]}$ the typically microcrystalline $2 \mathrm{D}$ covalent organic frameworks $(\mathrm{COF})^{[14,15]}$ with 2D polymers of the structural characteristics discussed here.

Several review articles have appeared on 2D polymers in the few years since 2012, where all these strategies are explained in detail.[16] Some of the articles treat 2D polymers more like (organic) 2D materials, which they are, and some take the vantage point of polymer chemistry, placing emphasis on the presence of repeat units to describe the entirety of a macromolecule. In an attempt to advance and shape a developing field, another article, which appeared in 2019, provides a substantial look into the near- and medium-range future. ${ }^{[17]}$ All these articles address to a greater or lesser extent the issues of structural analysis and structural perfection, which are formidable challenges considering the outrageously large number of atoms which need to be connected to one another in a $2 \mathrm{D}$ polymer in a long-range ordered fashion. A square micrometer of such a sheet can easily reach molar masses of several hundred MDa, which makes such polymers the largest ever-synthesized macromolecules with molecular precision. [18]

This article in the themed issue of Chimia on 'Dimensionality in Chemistry' focuses on the latest developments rather than on re-presenting material already treated in these overviews. We present four brand-new monomers and discuss how they are expected to advance the field of 2D polymers in different directions. They were all designed for the air/water interface. With two of them, we propose an indirect analysis method to predict the extent to which the corresponding covalent monolayers have long-range order. We believe this method to be useful when direct structural analysis e.g. by imaging and scattering techniques such as scanning tunneling microscopy (STM), high resolution atomic force microscopy (HR-AFM) and selected area electron diffraction (SAED) still requires considerable effort, availability of high-level craftsmanship and, most importantly, a significant portion of luck. The essence is a combination of a crystallization model for tri-functional, planar monomers with an analytical tool, e.g. tip-enhanced Raman spectroscopy (TERS) that provides two ingredients: a proof for how the monomers are connected to one another in the 2D polymer and an experimentally determined number for the polymerization conversion. With the two remaining monomers we describe more application-oriented advances in terms of writing into 'molecular paper' and of performing lithography, whereby the underlying writing and lithographic steps are $2 \mathrm{D}$ polymerizations in predetermined parts of dense monolayers of specially designed monomers after transfer onto solid substrates. The article closes with a brief summary and an outlook for where the story will go with this exciting class of long-range ordered sheets.

\section{How to Indirectly Determine the Crystallinity Degree of Monolayer 2D Polymers}

Monomers are the key to polymers. It is therefore natural to invest every effort into designing and synthesizing the corresponding monomers when establishing a new class of polymers. Fig. 2 shows a collection of the currently available monomers grouped into those suitable for the single crystal approach (named SC1-SC6, Fig. 2a) and those for the air/water interface approach (named AW1-AW9, Fig. 2b). In contrast to the former monomers, it could not be unequivocally proven for all of the latter ones yet, e.g. by imaging methods, that the products of polymerization do exhibit long-range order and thus qualify as $2 \mathrm{D}$ polymers. This is due to complications associated with structural analysis of monolayers. While one increasingly understands better how to handle 1-2 nm thin, macroscopically extended 2D polymer layers and how to prepare specimens suitable for analysis, the whole matter remains challenging and is rather time consuming. Some of the problems have been described elsewhere.[16e] This situation has the potential to slow down the desired development of the field and strategies are therefore being developed in parallel with the goal to offer indirect evidence for the degree of structural perfection. While an indirect structural proof can never fully replace a direct one, it helps the decision for which cases direct structural analysis is worth putting effort into.

This is the point at which the most recent monomers AW8 and AW9 step in. ${ }^{[19]}$ Before explaining their role for the analysis of the 2D homo- and copolymers obtained from them at an air/water interface, however, a few words should be devoted to a description of the chronology of insights that eventually led to their design and realization. A few years ago, the Zenobi group showed that TERS is sensitive enough to obtain critical information about bonding in monolayers and that this information can be combined with the lateral resolution of scanning probe microscopy (SPM). ${ }^{[20]}$ For a partially polymerized monolayer of monomer AW4, after transfer onto a Au substrate to utilize the sensitivity increase due to plasmon resonances, they could show reduced intensity of diazaanthracene-typical signals. This is exactly what to expect if the proposed [4+4]-cycloaddition reaction between neighboring monomers actually takes place. While this result was far away from an unequivocal structural analysis, it pointed in a promising direction. Shortly thereafter, and after an excursion into the analysis of an imine-based monolayer network, ${ }^{[21]}$ a breakthrough in monolayer analysis by TERS was obtained for monomer AW6. ${ }^{[171]}$ Now not only the partial disappearance of a signal typical for monomer but also the simultaneous appearance of a new signal typical for the bridgehead atoms of the corresponding $2 \mathrm{D}$ polymer was clearly seen. This was clear proof for polymerization and enabled the conversion to be estimated at approximately $90 \% .{ }^{[8]}$ In combination with conventional tapping mode AFM confirming the investigated material to be in fact monolayer throughout, these findings suggested high crystallinity. Gratifyingly, this prediction could be validated independently by non-contact HR-AFM imaging using the second-pass technique (Fig. 1). ${ }^{[8]}$ The image shows a porous $2 \mathrm{D}$ network highly regular over an area of $120 \times 120 \mathrm{~nm}^{2}$ ! Interestingly, impurities unintentionally but luckily present on the substrate are tightly 'enveloped', reflecting the softness of this molecular-scale fishing net. Wouldn't a real fishing net when lying stretched for drying on a quay wall with a few protrusions look exactly like this?

The fact that the initial TERS-based qualitative prediction could be confirmed so beautifully by an independent imaging method, made us aware of two important issues: First, TERS data have the potential to be used to predict crystallinity quantitatively, assuming the spectral quality is sufficient and signal assignment is ensured by DFT modelling, and a proper crystallization model is at hand. Second, molecular scale imaging does not necessarily have to be applied to each new 2D polymer, but rather can be limited to the particularly important cases. This way, much work (and frustration) can be spared and progress of the field can be accelerated.

Random growth theory ${ }^{[22]}$ is the appropriate tool to derive a polymerization model for a monomer of given functionality. It requires a few prerequisites to be met: (a) polymerization proceeds randomly and is chemoselective (e.g. exclusively based on [4+4]-cycloaddition dimerizations between monomers), (b) polymerization takes place exclusively in the plane defined by the initial locations of the reactive groups, and (c) polymerization conversion $X$ is accessible with sufficient accuracy. From our work in single crystals, condition (a) appeared rather likely to be fulfilled.[23] Whether condition (b) was met could be positively decided by height determination using conventional AFM imaging. Condition (c) finally depended on the quality of the individual TER spectra recorded and a proper statistical treatment of the hundreds of spectra recorded for a typical TERS map. 
Single crystal approach

(a)

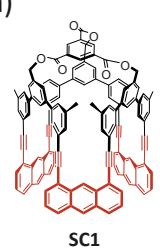

2012

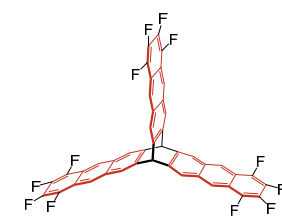

SC2
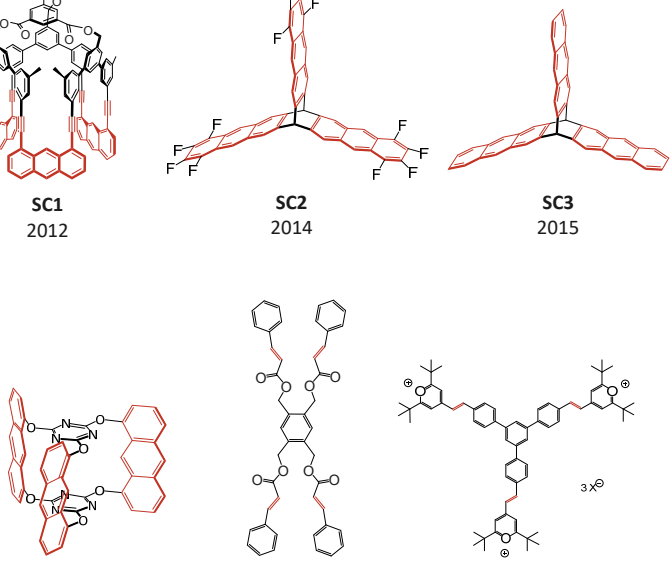

SC4

2014

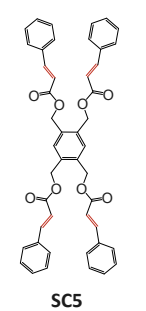

2015
2015

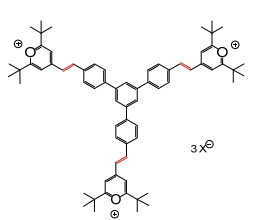

SC6 (b)

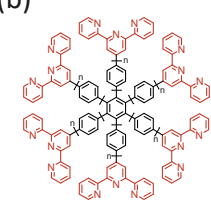

AW1

2011, 2013, 2014

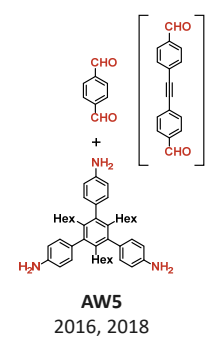

Air/water interface approach
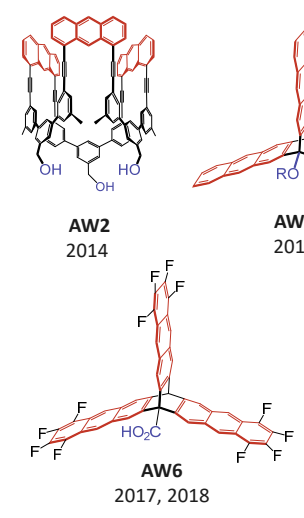

AW3
2015
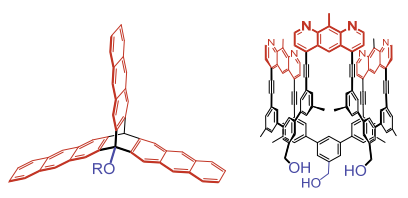

AW4

2015, 2017
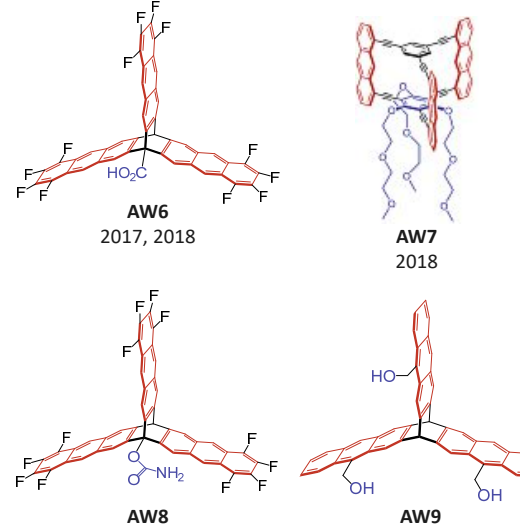

2019

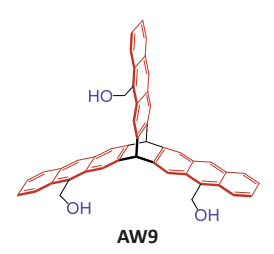

2019

Fig. 2. Chemical structures of monomers provided by the laboratories of King, Chu and the author and used for two-dimensional polymerization aiming at the synthesis of 2D polymers. Monomers employed in (a) the single-crystal approach and (b) the air/water interface approach. Reactive sites are in red, hydrophilic groups providing amphiphilicity in blue. For additional monomers by e.g. the Feng group, see ref. [7k].

From that moment on, brainstorming started aimed at selecting new monomers that enable facile quantitative TERS analysis and developing a model that predicts crystallinity degree $(C)$ and average diameter (and size) of defect-free regions based on conversion number $(X)$. Concerning monomer structure, we decided not to depart too much from the successful monomer AW6 and devised the amphiphilic structures AW8 and AW9. ${ }^{[19]}$ Both promised to have well-separated signals for the undisturbed (not yet reacted) anthracene blade breathing modes and for the bridgehead stretching vibrations in the TER spectra, which had proven so useful in the case of AW6. Furthermore, AW8, like AW6, is partially fluorinated, which should facilitate the proper alignment between the anthracene blades of neighboring monomers. ${ }^{[24]}$ The non-fluorinated AW9 was of interest to test whether or not partial fluorination is indispensable for bringing about high crystallinity. Finally, both monomers have the same propeller structure and the same size, which bears potential concerning the synthesis of copolymers by employing these monomers in varying feed ratios, very much as is done in conventional linear copolymerization of vinyl monomers. ${ }^{[25,26]}$

The monomers were synthesized using conventional routes and spread into monolayers on a Langmuir trough in pure form and as mixtures of several compositions including AW8:AW9 $=1: 1.2 \mathrm{D}$ polymerization was triggered by photoirradiation of $\mathrm{cm}^{2}$-sized areas using a conventional $365 \mathrm{~nm}$ UV lamp. After transfer of the photoproducts onto silicon wafers, conventional AFM analysis showed homogeneous films of constant thickness $h_{\mathrm{AFM}} \sim 1 \mathrm{~nm}$, confirming them to be a monolayer. In the following, these monolayers are referred to as 2DP8, 2DP9 and $\mathbf{2 D P 8}_{50} \mathbf{9}_{50}$. All three monomer monolayers (Figs. 3a-c, green spectra) and three corresponding polymer monolayers (Figs. 3a-c, blue spectra) were transferred onto Au substrates and average TER spectra recorded from $100 \times 100 \mathrm{~nm}^{2}$ maps (not shown) with $3 \times 3$ $\mathrm{nm}^{2}$ pixels resolution. Importantly, the typical monomer signal at $1440 \mathrm{~cm}^{-1}$ was almost completely absent in the polymer spectra, while the polymer spectra showed a signal at $960 \mathrm{~cm}^{-1}$, which is typical for anthracenes dimerized through [4+4]-cycloaddition. This signal is absent in the monomer spectra. This is clear spectral evidence for the proposed polymerization to have taken place to a high conversion. Quantitative data analysis after normalization afforded average conversion numbers of: $92.0 \pm 1.1 \%$ for $\mathbf{2 D P 8}, 87.7 \pm 1.8 \%$ for $\mathbf{2 D P 9}$ and $94.1 \pm 2.1 \%$ for $\mathbf{2 D P 8}_{\mathbf{5 0}} \mathbf{9}_{\mathbf{5 0}}$. The TERS maps exhibit a more or less uniform blue tone with a few dark blue pixels due to unreacted monomer and a few yellow/orange pixels due to random noise of contaminations in the junction between tip and sample. This reflects the considerable structural homogeneity of all three polymers.

Next, we concentrated on the crystallization model and the Kröger group found that under the mentioned prerequisites and for trifunctional monomers with equally reactive growth units, like the ones employed here, the crystallinity degree $C$ correlates with the conversion number $X$ according to the expression $C=$ $3 X^{2}-2 X^{3}$. ${ }^{[19]}$ This led to a couple of interesting conclusions: 1 ) For $\mathrm{X}>50 \%$ the crystallinity degree $C$ is higher than $X: C>X$. 2) The percolation threshold is reached already for the relatively low conversion number $X=65.3 \%$. 3) For the conversion numbers $80 \%, 85 \%$ and $90 \%$ the average diameters of defect regions are approximately 7,14 , and $30 \mathrm{~nm}$. Two representative networks for the $X$ values $X=80 \%$ and $X=95 \%$ are shown in Fig. 4. With this model, the conversion determined by TERS translates into crystallinity degrees $C$ of $98.2 \%$ (2DP8), $95.8 \%$ (2DP9) and $99.0 \%$ $\left.\left(\mathbf{D D P 8}_{50} \mathbf{9}_{50}\right) .4\right)$ The average diameter of defect-free crystalline regions in the monolayers studied is in the range of 3-30 $\mathrm{nm}$. These diameters correspond to areas of approximately $7-700 \mathrm{~nm}^{2}$. While the insights this method provides are thrilling, one must be aware of the conditions that must be met for its applicability, namely a sufficiently high quality of spectral information to determine the degree of conversion with sensible accuracy.

\section{Two-dimensional Polymerization for Optical Writing and Lithography}

After this excursion into an indirect structural analysis of 2D polymers, we now turn our attention to monomers AW4[27] and AW7 ${ }^{[28]}$ that, although still far away from a commercial application, point towards possible fields in which 2D polymer monolayers may reach societal relevance. Both cases concern photochemically triggered $2 \mathrm{D}$ polymerizations in reactive packings of monomers in compact monolayers as a means for either ink-free 


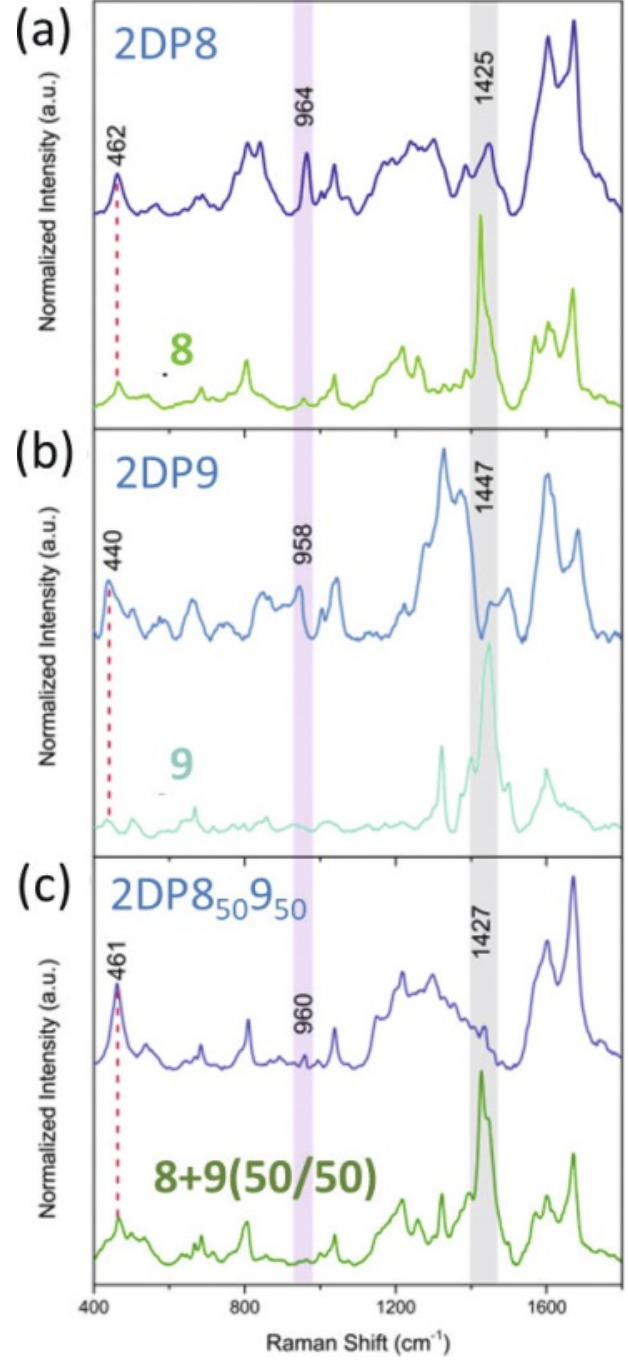

Fig. 3. Normalized average TER spectra of pairs of corresponding monomer and 2D polymer monolayers 2DP8, 2DP9, and $2 \mathbf{D P B}_{50} \mathbf{9}_{50}$ recorded after transfer to $\mathrm{Au}(111)$ substrates. The specific bands for monomers (around $1425 \mathrm{~cm}^{-1}$ ) and polymers (around $960 \mathrm{~cm}^{-1}$ ) are highlighted and discussed in the text. TERS maps are not shown.

reversible optical writing or as negative photoresists to provide 2D polymers of predetermined size and shape. Although polymerization can be affected directly at the air/water interface, e.g. with a blue handheld laser, it was an important point to show that the monolayers can be transferred to solid substrates prior to polymerization with full maintenance of their activity. This enables the reactive layers to be incorporated into devices and the photochemistry to be performed reproducibly and spatially confined with the help of a confocal laser-scanning microscope (CLSM).

Fig. 5a shows three fluorescence images of a monolayer of monomer AW4 on $\mathrm{C}_{18}$-SAM recorded with a $\lambda=458 \mathrm{~nm}$ excitation beam. The left hand image refers to a $850 \times 850 \mu \mathrm{m}^{2}$ section with some cracks that occurred during transfer. The center image was recorded after $2 \mathrm{D}$ polymerization had been induced with the $405 \mathrm{~nm}$ laser of the microscope, whereby the irradiated area, the sign '2DP', bleached completely. Within this area, all pairs of face-to-face stacked diazaanthracenes of neighboring monomers were effectively converted into their corresponding diazaanthracene dimers, which do not fluoresce. The right hand image provides an overview of the entire sample by assembling $6 \times 6$ images with the bleached '2DP' in the center. Assuming the mechanism is correct, bleaching should be reversible e.g. by thermal treatment. And, yes, in fact, if this sample is placed in an oven at $200{ }^{\circ} \mathrm{C}$ for $2 \mathrm{~h}$, the sign '2DP' disappears and fluorescence is fully recovered. Thus, the monolayer of monomer AW4 behaves as if it was a conventional photographic film based on celluloid except that the information is encoded by fluorescence bleaching and that the film is only $1.5 \mathrm{~nm}$ thick. While reaching the nano range has been achieved in electronics, ${ }^{[29]}$ for optics such a quest is still in its early phase: Device sizes well below the diffraction limit of light have been reported in a few cases only. ${ }^{[30]}$

The other monomer, AW7, was used for lithography. For this, the strongly fluorescing monomer monolayer was transferred onto a silicon wafer and partially masked with single-hole TEM grids (Fig. 5b). Upon irradiation with a $385 \mathrm{~nm}$ light-emitting diode the fluorescence gradually disappeared in all non-covered areas. Upon removal of unreacted monomer by washings, circular 2D polymer monolayer objects remained, where the centers of the TEM grid masks had been. Although the color contrast provided by the differential interference optical microscopy images in Fig. 5c,d is not strong, one can still see the sky-blue polymerized monolayer surrounded by the more purple bare substrate. Apart from its interesting lithographical aspect, this work also shows that polymerization is strictly confined to the irradiated areas $^{[31]}$ and that this way the molar mass can be controlled. Each circular feature, assuming structural perfection, corresponds to one two-dimensional macromolecule, the molar mass of which scales with the area.

\section{Summary and Outlook}

The fact that the long-range order in monolayer covalent films of monomer AW6 could recently be proven unambiguously by AFM (Fig. 1) shows that 2D polymers are not only accessible in the single crystal but also at an air/water interface. This gave
Fig. 4. Model connecting polymerization conversion with crystallinity. Two representatives of small 2D networks obtained for $X=80 \%$ and $95 \%$. Coloring scheme: Bonds (edges) can be either 'unreacted' (grey), reacted (green), or reacted and belonging to a fully reacted monomer (black). Monomers can have 0 (not shown), 1 (red), 2 (green), or 3 (black) reacted bonds. A defective site has less than 2 reacted bonds, because a site with 2 reacted bonds still contributes to the formed 2D polymer, often residing at the interface to a defect. system at $C=80 \%$ conversion

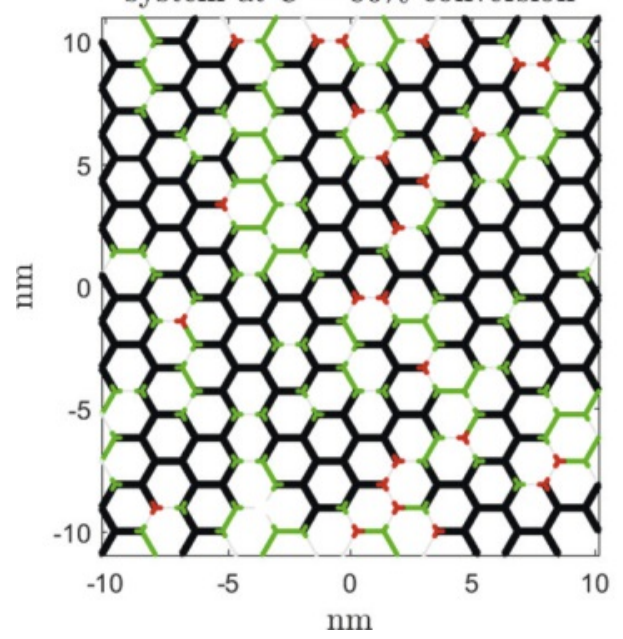

system at $C=95 \%$ conversion

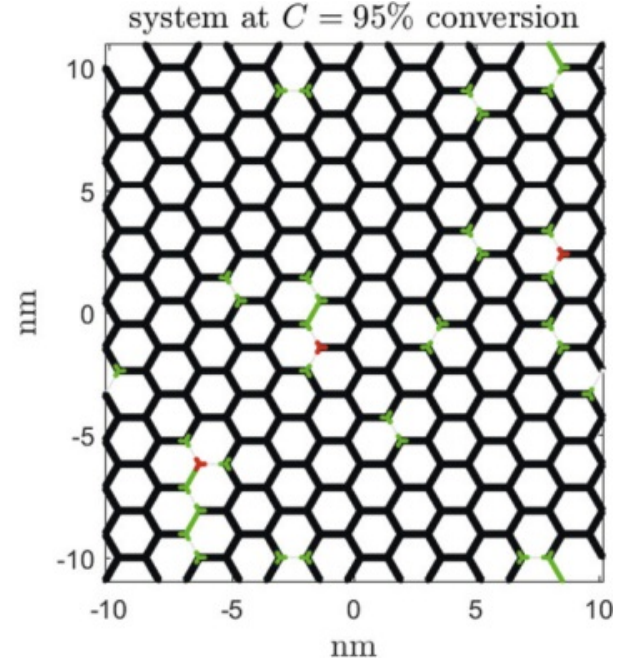



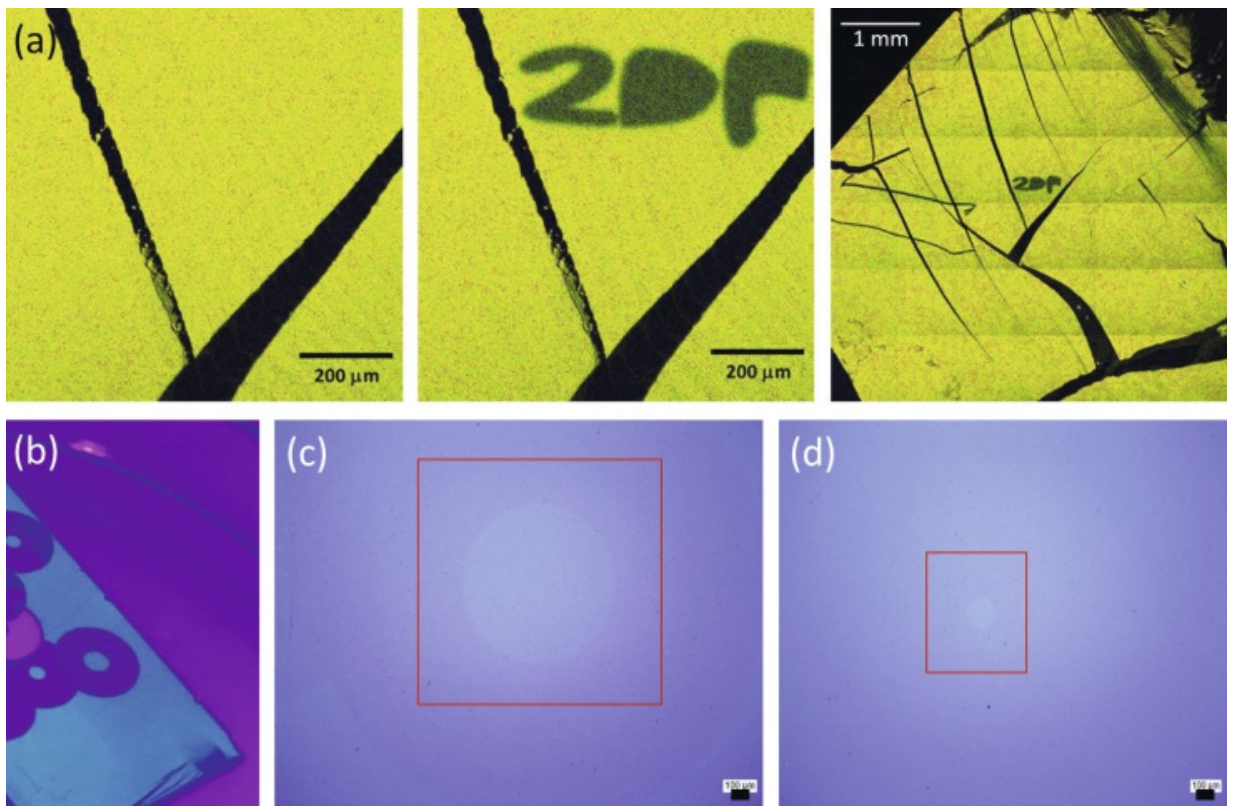

Fig. 5. 2D polymerizations in monolayers with 'reactive packing' for optical writing and lithography. (a) Fluorescence images of spread monomer AW4 after transfer onto a $\mathrm{C}_{18}$-self-assembled monolayer as obtained (left) and after bleaching the sign '2DP' with the $405 \mathrm{~nm}$ laser of a confocal laser scanning microscope (center); several square mm sized overview image of the sample (right). (b) Monomer AW7 monolayer-coated silicon wafer with single-holed TEM grids as masks placed on top. Upon irradiation with a $385 \mathrm{~nm}$ LED, the fluorescence (here shown in blueish-green) disappears as polymerization progresses. (c,d) Optical micrographs in differential interference contrast showing two differently sized sky-blue irradiated circular areas created by the masks in (b) highlighted by red squares, which - provided structural perfection - are 2D polymers of monomer AW7. The samples were washed with chloroform and isopropanol to remove all non-polymerized monomers prior to imaging. The area surrounding the circles is bare silicon oxide and therefore appears purple. Black scale bars in (c) and (d): $100 \mu \mathrm{m}$. Reprinted in parts with permission by the publisher.

the whole field a push and is one of the reasons why the author's group came up with four new monomers to be employed at this interface. For homo- and copolymers of two of these monomers, a method for indirect structure elucidation was described. It combines the TER spectroscopic proof for bond formation between monomers and the achieved polymerization conversion with a crystallization model. Under certain prerequisites, this allows the crystallization degree of a 2D polymer to be estimated and, thus, to evaluate for which of the covalent monolayer sheets it makes most sense to apply the laborious direct imaging or scattering techniques in order to provide a direct structural proof. For the remaining two monomers the article shows how (reversible) twodimensional polymerization of monomer monolayers can be used for laser-induced optical writing and lithography. Both processes can be carried out under mild conditions with full control of the chemical reactions taking place.

While quantity plays a crucial role for monomers suitable for the single crystal approach, the mass of pure monomer for the interface approach is less important. Even a few tens of milligram in principle already suffice to run a (not yet developed) continuous $2 \mathrm{D}$ polymerization process. What matters nevertheless though is the simplicity with which access can be provided: In terms of synthesis, this concerns the required steps, the overall duration from commercially available compounds and the amounts available per run. For the following three monomers, the numbers are AW7: 9, 1 month, $400 \mathrm{mg}$; AW8: 6, 2 weeks, > $100 \mathrm{mg}$, and AW9: 5, 2 weeks, > $100 \mathrm{mg}$. For a synthesis lab, this is well within the norm and it is fair to conclude that these monomers are conveniently accessible. Given the tiny amounts needed, costs are not so relevant.

Besides the four discussed monomers, this article also provides an overview of the currently available 15 monomers for the synthesis of $2 \mathrm{D}$ polymers. Given this respectable number, it is tempting to have a preliminary look into potential structural similarities. The anthracene (or 1,8-diazaanthracene) units in Fig. 2 catch the eye, as they are the most widely employed growth units in the given collection. Eleven out of 15 monomers rely on them! It thus appears as if anthracene growth units have a comparable importance for two-dimensional polymerization as olefins have for linear polymerization. This concerns both the crystal and the interfacial approach. Supposed one accepts this picture, monomers SC2, SC3 and AW4 correspond to, for example, ethylene fluoride, parent ethylene and a fluorinated methacrylic acid in vinyl polymerization. This is to say that our laboratory does not consider the apparently subtle structural differences among the anthracene-based monomers to be subtle at all. They will rather turn out to be critically important in terms of properties very much as it happened for the acrylate and the methacrylate families decades ago. Both families have distinctly different application portfolios, despite the fact that structurally they differ by one methyl group per repeat unit only. We expect the future to bring out other dominant growth motifs besides anthracene.

The polymerizations described in this brief article allow for spanning several length scales between monomer and sheet-like product with full structural control and in a matter of minutes at room temperature. Not only are such polymers unique in polymer chemistry but they are also much more easily accessible than we ourselves had thought when starting the work towards this fascinating goal in 2002. 2D polymers will not only be important for down-sized optical devices and chemically defined lithography as described in this article but - given their nanoporous nature also for gas permeation and separation, sensing applications, and the like.

\section{Acknowledgements}

I cordially thank all my co-workers and collaboration partners for making $2 \mathrm{D}$ polymers a reality. Without their ingenious and creative contributions and their hard work, this would not have happened. I am indebted to Drs Vivian Müller, Timo Niepel, Marco Servalli and Wei Wang for critically reading the manuscript. This work was supported by the Swiss National Science Foundation, which is gratefully acknowledged. 
[1] H. Staudinger, Ber. Dtsch. Chem. Ges. 1920, 53, 1073.

[2] P. Kissel, R. Erni, W. B. Schweizer, M. D. Rossell, B. T. King, T. Bauer, S. Götzinger, A. D. Schlüter, J. Sakamoto, Nat. Chem. 2012, 4, 287.

[3] J. Sakamoto, J. van Heijst, O. Lukin, A. D. Schlüter, Angew. Chem. Int. Ed. 2009, 48, 1030.

[4] a) J. W. Colson, W. R. Dichtel, Nat. Chem. 2013, 5, 453; b) X. Zhuang, Y. Mai, D. Wu, F. Zhang, X. Feng, Adv. Mater. 2015, 27, 403; c) K. Baek, I. Hwang, I. Roy, D. Shetty, K. Kim, Acc. Chem. Res. 2015, 48, 2221; d) C. E. Boott, A. Nazemi, I. Manners, Angew. Chem. Int. Ed. 2015, 54, 13876; e) M. Lackinger, Polym. Int. 2015, 64, 1073; f) R. Sakamoto, T. Iwashima, M. Tsuchiya, R. Toyoda, R. Matsuoka, J. F. Kogel, S. Kusaka, K. Hoshiko, T. Yagi, T. Nagayama, H. Nishihara, J. Mater. Chem. A 2015, 3, 15357; g) D. Rodríguez-San-Miguel, P. Amo-Ochoa, F. Zamora, Chem. Commun. 2016, 52,4113 .

[5] M. Servalli, H. C. Öttinger, A. D. Schlüter, Phys. Today 2018, 71, 40.

[6] a) R. Bhola, P. Payamyar, D. J. Murray, B. Kumar, A. J. Teator, M. U. Schmidt, S. M. Hammer, A. Saha, J. Sakamoto, A. D. Schlüter, B. T. King, J. Am. Chem. Soc. 2013, 135, 14134; b) P. Kissel, D. J. Murray, W. J. Wulftange, V. J. Catalano, B. T. King, Nat. Chem. 2014, 6, 774; c) M. J. Kory, M. Wörle, T. Weber, P. Payamyar, S. W. van de Poll, J. Dshemuchadse, N. Trapp, A. D. Schlüter, Nat. Chem. 2014, 6, 779; d) Z. Wang, K. Randazzo, X. Hou, J. Simpson, J. Struppe, A. Ugrinov, B. Kastern, E. Wysocki, Q. R. Chu, Macromolecules 2015, 48, 2894; e) R. Z. Lange, G. Hofer, T. Weber, A. D. Schlüter, J. Am. Chem. Soc. 2017, 139, 2053. Also, see: W. Liu, X. Luo, Y. Bao, Y. P. Liu, G.-H. Ning, I. Abdelwahab, L. Li, C. T. Nai, Z. G. Hu, D. Zhao, B. Liu, S. Y. Quek, K. P. Loh, Nat. Chem. 2017, 9, 563.

[7] a) T. Bauer, Z. Zheng, A. Renn, R. Enning, A. Stemmer, J. Sakamoto, A. D. Schlüter, Angew. Chem. Int. Ed. 2011, 50, 7879; b) Z. Zheng, C. S. RuizVargas, T. Bauer, A. Rossi, P. Payamyar, A. Schutz, A. Stemmer, J. Sakamoto, A. D. Schlüter, Macromol. Rapid Commun. 2013, 34, 1670; c) Y. Chen, M. Li, P. Payamyar, Z. Zheng, J. Sakamoto, A. D. Schlüter, ACS Macro Lett. 2014, 3, 153; d) P. Payamyar, K. Kaja, C. Ruiz-Vargas, A. Stemmer, D. J. Murray, C. J. Johnson, B. T. King, F. Schiffmann, J. VandeVondele, A. Renn, S. Götzinger, P. Ceroni, A. P. Schütz, L.-T. Lee, Z. Zheng, J. Sakamoto, A. D. Schlüter, Adv. Mater. 2014, 26, 2052; e) P. Payamyar, M. Servalli, T. Hungerland, A. P. Schütz, Z. Zheng, A. Borgschulte, A. D. Schlüter, Macromol. Rapid Commun. 2014, 36, 151; f) D. J. Murray, D. D. Patterson, P. Payamyar, R. Bhola, W. Song, M. Lackinger, A. D. Schlüter, B. T. King, J. Am. Chem. Soc. 2015, 137, 3450; g) R. Sakamoto, K. Hoshiko, Q. Liu, T. Yagi, T. Nagayama, S. Kusaka, M. Tsuchiya, Y. Kitagawa, W.-Y. Wong, H. Nishihara, Nat. Comm. 2015, 6, 6713; h) K. Takada, R. Sakamoto, S.-T. Yi, S. Katagiri, T. Kambe, H. Nishihara, J. Am. Chem. Soc. 2015, 137, 4681; i) W. Dai, F. Shao, J. Szczerbinski, R. McCaffrey, R. Zenobi, Y. Jin, A. D. Schlüter, W. Zhang, Angew. Chem. Int. Ed. 2016, 55, 213; j) R. Matsuoka, R. Sakamoto, K. Hoshiko, S. Sasaki, H. Masunaga, K. Nagashio, H. Nishihara, J. Am. Chem. Soc. 2017, 139, 3145; k) H. Sahabudeen, H. Qi, B. A. Glatz, D. Tranca, R. Dong, Y. Hou, T. Zhang, C. Kuttner, T. Lehnert, G. Seifert, U. Kaiser, A. Fery, Z. Zheng, X. Feng, Nat. Commun. 2016, 7, 13461; 1) V. Müller, F. Shao, M. Baljozovic, M. Moradi, Y. Zhang, T. Jung, W. B. Thompson, B. T. King, R. Zenobi, A. D. Schlüter, Angew. Chem. Int. Ed. 2017, 56, 15262.

[8] V. Müller, A. Hinaut, M. Moradi, M. Baljozovic, T. A. Jung, P. Shahgaldian, H. Möhwald, G. Hofer, M. Kröger, B. T. King, E. Meyer, T. Glatzel, A. D. Schlüter, Angew. Chem. Int. Ed. 2018, 57, 10584.

[9] a) T.-Y. Zhou, F. Lin, Z.-T. Li, X. Zhao, Macromolecules 2013, 46, 7745; b) K. Baek, G. Yun, Y. Kim, D. Kim, R. Hota, I. Hwang, D. Xu, Y. H. Ko, G. H. Gu, J. H. Suh, C. G. Park, B. J. Sung, K. Kim, J. Am. Chem. Soc. 2013, 135, 6523; c) J. Liu, W. Zan, K. Li, Y. Yang, F. Bu, Y. Xu, J. Am. Chem. Soc. 2017, 139, 11666.

[10] Q. Fan, J. M. Gottfried, J. Zhu, Acc. Chem. Res. 2015, 48, 2484.

[11] a) Y. Lin, X. Jiang, S. T. Kim, S. B. Alahakoon, X. Hou, Z. Zhang, C. M. Thompson, R. A. Smaldone, C. Ke, J. Am. Chem. Soc. 2017, 139, 7172; b) H. Yu, D. T. L. Alexander, U. Aschauer, R. Häner, Angew. Chem. Int. Ed. 2017, 56, 5040.

[12] a) Y. Liu, Y. Ma, Y. Zhao, X. Sun, F. Gándara, H. Furukawa, Z. Liu, H. Zhu, C. Zhu, K. Suenaga, P. Oleynikov, A. S. Alshammari, X. Zhang, O. Terasaki, O. M. Yaghi, Science 2016, 351, 365; b) Y. Zhao, L. Guo, F. Gándara, Y. Ma, Z. Liu, C. Zhu, H. Lyu, C. A. Trickett, E. A. Kapustin, O. Terasaki, O. M. Yaghi, J. Am. Chem. Soc. 2017, 139, 13166; c) U. Lewandowska, W. Zajaczkowski, S. Corra, J. Tanabe, R. Borrmann, E. M. Benetti, S. Stappert, K. Watanabe, N. A. K. Ochs, R. Schaeublin, C. Li, E. Yashima, W. Pisula, K. Müllen, H. Wennemers, Nat. Chem. 2017, 9, 1068; d) Z. Wang, A. Błaszczyk, O. Fuhr, S. Heissler, C. Wöll, M. Mayor, Nat. Commun. 2017, 8, 14442; e) Y. Liu, M. O'Keeffe, M. M. J. Treacy, O. M. Yaghi, Chem. Soc. Rev. 2018, 47, 4642.

[13] a) A. M. Evans, L. R. Parent, N. C. Flanders, R. P. Bisbey, E. Vitaku, M. S. Kirschner, R. D. Schaller, L. X. Chen, N. C. Gianneschi, W. R. Dichtel, Science 2018, 361, 52; b) T. Ma, E. A. Kapustin, S. X. Yin, L. Liang, Z. Zhou, J. Niu, L. Li, Y. Wang, J. Su, J. Li, X. Wang, W. D. Wang, W. Wang, J. Sun, O. M. Yaghi, Science 2018, 361, 48.
[14] a) A. P. Côté, A. I. Benin, N. W. Ockwig, M. O’Keeffe, A. J. Matzger, O. M. Yaghi, Science 2005, 310, 1166; b) A. P. Côté, H. M. El-Kaderi, H. Furukawa, J. R. Hunt, O. M. Yaghi, J. Am. Chem. Soc. 2007, 129, 12914; c) F. J. Uribe-Romo, J. R. Hunt, H. Furukawa, C. Klock, M. O'Keeffe, O. M. Yaghi, J. Am. Chem. Soc. 2009, 131, 4570; d) J. W. Colson, A. R. Woll, A. Mukherjee, M. P. Levendorf, E. L. Spitler, V. B. Shields, M. G. Spencer, J. Park, W. R. Dichtel, Science 2011, 332, 228; e) L. Ascherl, T. Sick, J. T. Margraf, S. H. Lapidus, M. Calik, C. Hettstedt, K. Karaghiosoff, M. Döblinger, T. Clark, K. W. Chapman, F. Auras, T. Bein, Nat. Chem. 2016, 8, 310.

[15] For related frameworks, see: a) P. Kuhn, M. Antonietti, A. Thomas, Angew. Chem., Int. Ed. 2008, 47, 3450; b) N. A. A. Zwaneveld, R. Pawlak, M. Abel, D.Catalin, D. Gigmes, D. Bertin, L. Porte, J. Am. Chem. Soc. 2008, 130, 6678 ; c) M. J. Bojdys, J. Jeromenok, A. Thomas, M. Antonietti, Adv. Mater. 2010, 22, 2202; d) J. F. Dienstmaier, A. M. Gigler, A. J. Goetz, P. Knochel, T. Bein, A. Lyapin, S. Reichlmaier, W. M. Heckl, M. Lackinger, ACS Nano 2011, 5, 9737; e) M. Bieri, S. Blankenburg, M. Kivala, C. A. Pignedoli, P. Ruffieux, K. Müllen, R. Fasel, Chem. Commun. 2011, 47, 10239; f) J. F. Dienstmaier, D. D. Medina, M. Dogru, P. Knochel, T. Bein, W. M. Heckl, M. Lackinger, ACS Nano 2012, 6, 7234; g) S. Ren, M. J. Bojdys, R. Dawson, A. Laybourn, Y. Z. Khimyak, D. J. Adams, A. I. Cooper, Adv. Mater. 2012, 24, 2357; h) X.-H. Liu, C.-Z. Guan, D. Wang, L.-J. Wan, $A d v$. Mater. 2014, 26, 6912; i) L. Xu, X. Zhou, W. Q. Tian, T. Gao, Y. F. Zhang, S. Lei, Z. F. Liu, Angew. Chem. Int. Ed. 2014, 53, 9564; j) G. Algara-Siller, N. Severin, S. Y. Chong, T. Bjçrkman, R. G. Palgrave, A. Laybourn, M. Antonietti, Y. Z. Khimyak, A. V. Krasheninnikov, J. P. Rabe, U. Kaiser, A. I. Cooper, A. Thomas, M. J. Bojdys, Angew. Chem. Int. Ed. 2014, 53, 7450; k) D. Schwarz, Y. Noda, J. Klouda, K. Schwarzová-Pecková, J. Tarábek, J. Rybáček, J. Janoušek, F. Simon, M. V. Opanasenko, J. Čejka, A. Acharjya, J. Schmidt, S. Selve, V. Reiter-Scherer, N. Severin, J. P. Rabe, P. Ecorchard, J. He, M. Polozij, P. Nachtigall, M. J. Bojdys, Adv. Mater. 2017, 29, 1703399 1) I. Janica, V. Patroniak, P. Samorì, A. Ciesielski, Chem. Asian J. 2018 , 13, 465. Also, see the work by Nishihara and Sakamoto: R. Sakamoto, T. Iwashima, M. Tsuchiya, R. Toyoda, R. Matsuoka, J. F. Kogel, S. Kusaka, K. Hoshiko, T. Yagi, T. Nagayama, H. Nishihara, J. Mater. Chem. A 2015, 3 , 15357; R. Sakamoto, K. Takada, T. Pal, H. Maeda, T. Kambe, H. Nishihara, Chem. Commun 2017, 53, 5781; R. Matsuoka, R. Sakamoto, K. Hoshiko, S. Sasaki, H. Masunaga, K. Nagashio, H. Nishihara, J. Am. Chem. Soc. 2017, 139,3145

[16] a) P. Payamyar, B. T. King, H. C. Öttinger, A. D. Schlüter, Chem. Commun. 2016, 52, 18; b) M. Servalli, Chimia 2017, 71, 359; c) M. Servalli, A. D. Schlüter, Аnnu. Rev. Mater. Res. 2017. 47, 361; d) H. Liu, X.-N. Kan, C.-Y Wu, Q.-Y. Pan, Z.-B. Li, Y.-J. Zhao, Chin. J. Polym. Sci. 2018, 36, 425; e) X. Feng, A. D. Schlüter, Angew. Chem. Int. Ed. 2018, 57,13748.

[17] W. Wang, A. D. Schlüter, Macromol. Rapid Commun. 2019, 1800719.

[18] B. Zhang, R. Wepf, K. Fischer, M. Schmidt, S. Besse, P. Lindner, B. T. King, R. Sigel, P. Schurtenberger, Y. Talmon, Y. Ding, M. Kröger, A. Halperin, A. D. Schlüter, Angew. Chem. Int. Ed. 2011, 50, 737.

[19] W. Wang, F, Shao, M. Kröger, R. Zenobi, A. D. Schlüter, submitted.

[20] a) L. Opilik, P. Payamyar, J. Szczerbinski, A. P. Schütz, M. Servalli, T. Hungerland, A. D. Schlüter, R. Zenobi, ACS Nano 2015, 9, 4252; b) F. Shao, R. Zenobi, Anal. Bioanal. Chem. 2019, 411, 37.

[21] a) W. Dai, F. Shao, J. Szczerbinski, R. McCaffrey, R. Zenobi, Y. Jin, A. D. Schlüter, W. Zhang, Angew. Chem. Int. Ed. 2016, 55, 213; b) F. Shao, W. Dai, Y. Zhang, W. Zhang, A. D. Schlüter, R. Zenobi, ACS Nano 2018, 12, 5021.

[22] M. Prahofer, H. Spohn, Phys. Rev. Lett. 2000, 84, 4882; b) J. Gravner, D. Griffeath, Ann. Probability. 2006, 34, 181.

[23] G. Hofer, F. Grieder, M. Kröger, A. D. Schlüter, T. Weber, J. Appl. Cryst. 2018, 51,481 .

[24] a) J. H. Williams, Acc. Chem. Res. 1993, 26, 593; b) Y-Y. Luk, N. L. Abbott, J. N. Crain, F. J. Himpsel, J. Chem. Phys. 2004, 120, 10792.

[25] J. M. G. Cowie, V. Arrigi, 'Chemistry and Physics of Modern Materials', CRC Press, Boca Raton, 2007; G. Odian, 'Principles of Polymerization', 4. Edn., Wiley, New York, 2004.

[26] R. F. Mayo, F. M. Lewis, J. Am. Chem. Soc. 1944, 66, 1594

[27] V. Müller, T. Hungerland, M. Baljozovic, T. Jung, N. D. Spencer, H. Eghlidi, P. Payamyar, A. D. Schlüter, Adv. Mater. 2017, 29, 1701220

[28] M. Servalli, K. Celebi, P. Payamyar, L. Zheng, M. Polozij, B. Lowe, A. Kuc, T. Schwarz, A. Borgschulte, K. Thorwarth, T. Heine, R. Zenobi, A. D. Schlüter, ACS Nano 2018, 12, 11294.

[29] B. Wu, A. Kumar, Appl. Phys. Rev. 2014, 1, 011104.

[30] a) M. Khorasaninejad, W. T. Chen, R. C. Devlin, J. Oh, A. Y. Zhu, F. Capasso, Science 2016, 352, 1190; b) E. Maguid, I. Yulevich, D. Veksler, V. Kleiner, M. L. Brongersma, E. Hasman, Science 2016, 352, 1202.

[31] G. Leggett, Nanoscale 2012, 4, 1840 